\title{
Mathematical Issues in Data Science and Applications for Health care
}

\author{
Sitti Zuhaerah Thalhah, Mohammad Tohir, Phong Thanh Nguyen, K. Shankar, Robbi Rahim
}

\begin{abstract}
For development in military applications, industrial and government the predictive analytics and decision models have long been cornerstones. In modern healthcare system technologies and big data analytics and modeling of multi-source data system play an increasingly important role. Into mathematical models in these domains various problems arising that can be formulated, by using computational techniques, sophisticated optimization and decision analysis it can be analyzed. This paper studies the use of data science in healthcare applications and the mathematical issues in data science.
\end{abstract}

Keywords- applications, decision analysis, data science, mathematical models

\section{INTRODUCTION}

From other professions the newcomers that arriving at data science it is important to have knowledge of essential math; this can be business management, the chemical process industry, hardware engineering health care and medicine etc. with projections, numerical calculations and spreadsheets these areas require experience. In data science the math skill that is necessary is quite different [1-2].

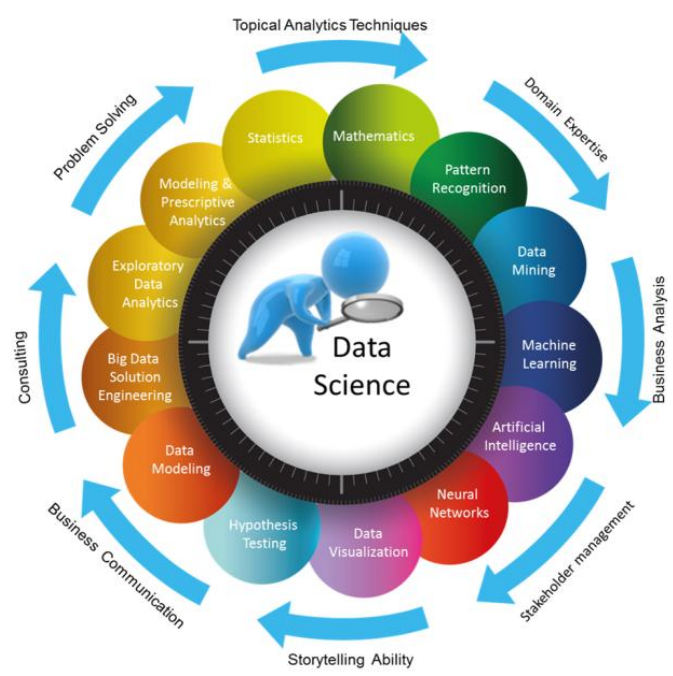

Revised Version Manuscript Received on 16 September, 2019.

* Correspondence Author

Sitti Zuhaerah Thalhah, Institut Agama Islam Negeri Palopo, Indonesia. E-mail: hera@iainpalopo.ac.id

Mohammad Tohir, Department of Mathematics Education, Universitas Ibrahimy, Situbondo, Indonesia.

Phong Thanh Nguyen*, Department of Project Management, Ho Chi Minh City Open University, Vietnam. E-mail: phong.nt@ou.edu.vn

K. Shankar, Department of Computer Applications, Alagappa University, India. E-mail: shankarcrypto@gmail.com

Robbi Rahim, Sekolah Tinggi Ilmu Manajemen Sukma, Medan, Indonesia
Figure 1: In Healthcare use of Data Science

\section{USE CASES OF DATA SCIENCE IN HEALTHCARE}

Every day the industry of healthcare generate a copious amount of data. To churn out large amount of information billing, data from wearables [3], clinical systems, various pieces of research and electronic medical records are used. From previous patient data by actionable insights to ensure better patient care powered for healthcare providers this presents a valuable opportunity. It can possible through data science.

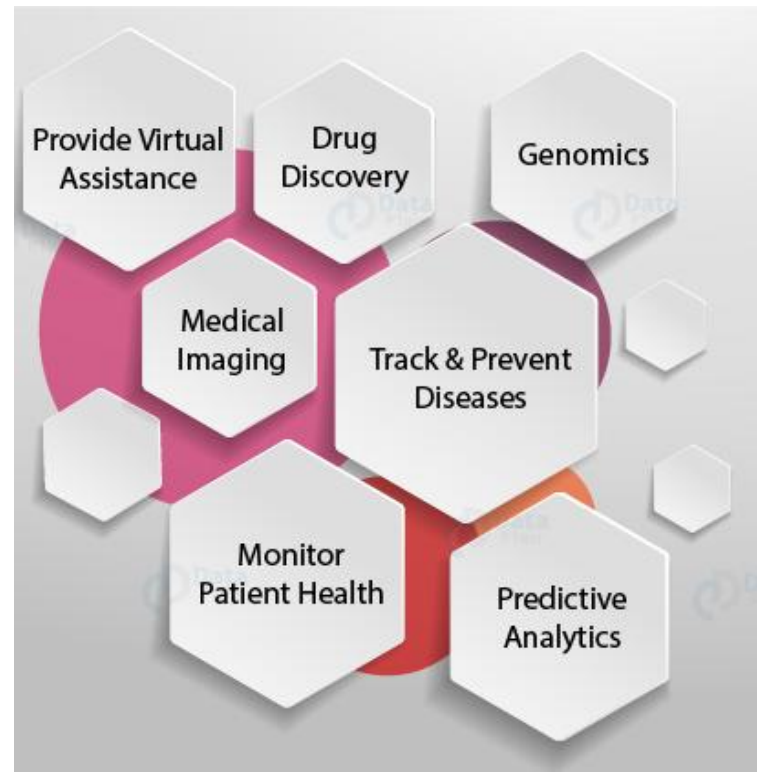

Figure 2: It Health care use of data science

Across the world the data scientists are gradually revolutionizing the healthcare industry of healthcare with the help of advanced analytics and machine learning. By unlocking the potential of data achieving operational experience and improving care delivery they work to optimize all aspects of healthcare operation [4].

\section{Diagnostics}

Which type of treatment to be provided to the patient is determined by diagnosis so it is consider as a critical part of the patient care cycle.

\section{Optimal staffing}

For care of patient at any given point in time to have adequate medical staff it increase the need of healthcare every time and several time it find challenging. In an inflexible schedule in patient flow any modification always affects the units working, like emergency care units and ICUs. It can increase the labor cost if there are more than enough staff is available [5]. 


\section{Health of Public}

To improve overall public health numerous associations of healthcare have just begun to use enormous information with an end goal. From various sources like social media, websites, Google maps and wearables there is a massive amount of scattered healthcare data. In a specific geography to understanding the overall public health this data holds the key. To prepare heatmaps pertaining to parameters such as restorative aftereffects of individuals in the geology, population, health ailments etc data scientists can analyze it [6].

\section{Discovery of Drug}

Development of drug is definitely not a basic procedure. It takes a lot of research, testing, time and money related venture before a drug is propelled in the market [7]. It is evaluated that the expense of offering another drug for sale to the public.

Information science can use different arrangements of organized and unstructured biomedical information got from various tests, treatment results, contextual investigations, online networking and so on crosswise over assorted controls. It would then be able to utilize progressed numerical calculations to make a reproduction of how the medication would cooperate with body proteins and anticipate the pace of accomplishment.

\section{Healthcare costs reduction}

The costs of healthcare just have all the earmarks of being ascending with time and this demonstrates to be an affecting element in conveying a predominant patient encounter. In any case, with BI tools and BI analytics, this can be tended to too. Information researchers can investigate charging information and data from clinical frameworks relating to classes of variables and charges. This enables them to penetrate down to the patterns in required resources and required room usage to take into account patient needs; along these lines, recognizing potential regions of revenue losses and operational gaps.

\section{Wearables Device}

Wearables are rapidly getting to be pervasive. Aside from making a cool embellishment, they empower self-wellbeing the executives in individuals. They record significant wellbeing readings like circulatory strain, pulse, rest design, beat and so forth [8].

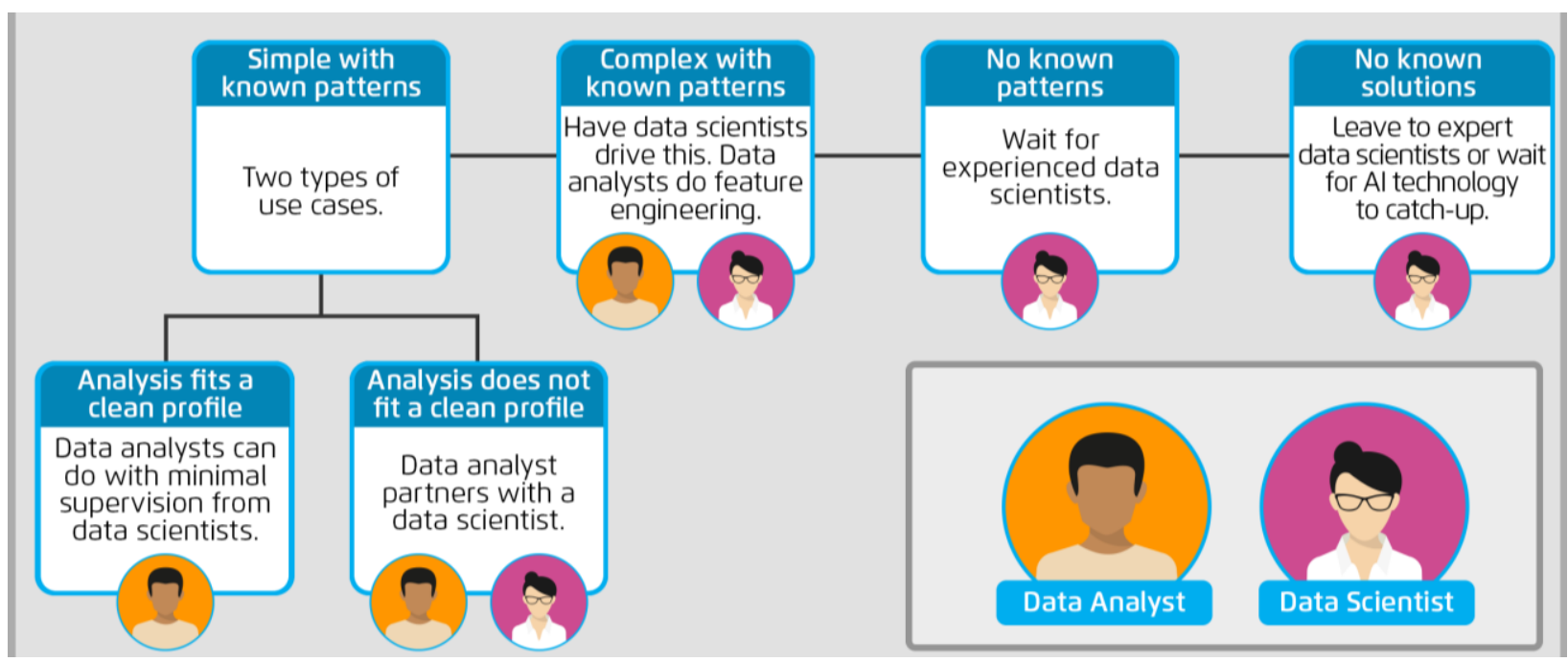

Figure 3: In Health care use cases

\section{Big Data Analytics in HealthCARE}

The idea of "big data" isn't new; anyway the manner in which it is characterized is continually evolving. Different endeavors at characterizing big data basically portray it as a gathering of information components whose size, speed, type, as well as unpredictability expect one to look for, embrace, and create new equipment and programming systems so as to effectively store, dissect, and envision the information [9-10]. Medicinal services is a prime case of how the three Vs of information, (speed of age of information), assortment, and volume [11], are a natural part of the information it produces. This information is spread among different human services frameworks, wellbeing back up plans, specialists, government substances, etc. Besides, every one of these information storehouses is siloed and innately unequipped for giving a stage to worldwide information straightforwardness. To add to the three Vs, the veracity of social insurance information is additionally basic for its important use towards creating translational research.

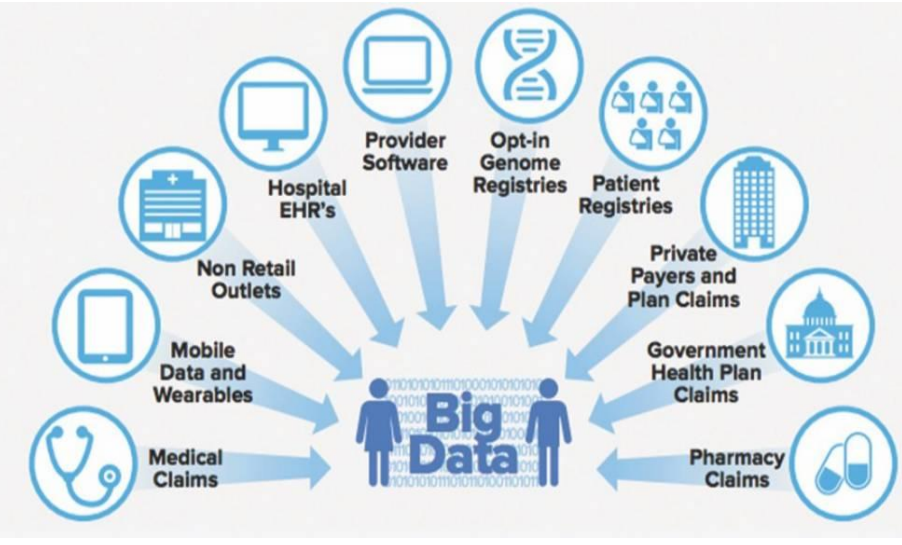

Figure 4: Big Data Analytic in Healthcare

Significant pathophysiological and physiological marvels are simultaneously showed as changes over different clinical streams. 
This outcome from solid coupling among various frameworks inside the body in this way delivering potential markers for clinical appraisal. Along these lines, understanding and foreseeing sicknesses require an accumulated methodology where organized and unstructured information coming from a bunch of nonclinical and clinical modalities are used for a progressively exhaustive point of view of the infection states. A part of explore of healthcare that has as of late picked up footing is in tending to a portion of the developing agonies in presenting ideas of big data analytics to medicine. Scientists are concentrating the healthcare data's complex nature regarding the two attributes of the taxonomy of analytics and characteristics of the data itself that can be seriously performed on them [12].

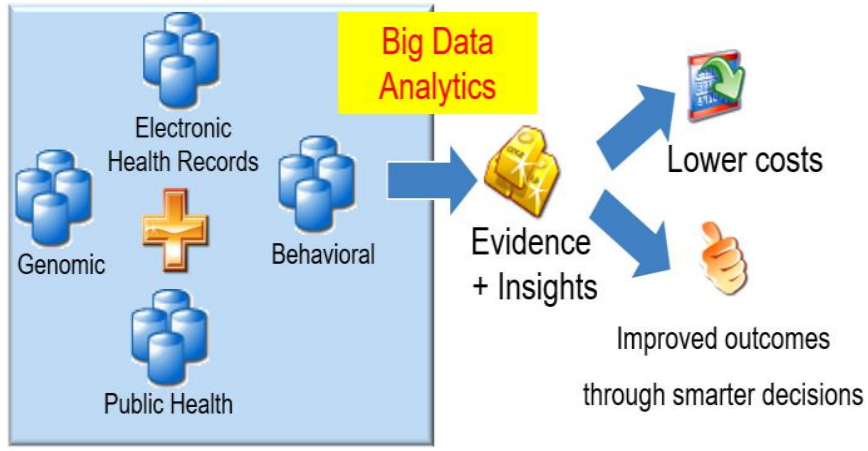

Figure 5: Healthcare Big data Analytics factors

Some challenges of big data are as follows:

1. Variability of Data. Notwithstanding the expanding transmission speeds and information assortments, information streams can be exceptionally conflicting with intermittent or non-occasional pinnacles. Thus, occasional, and non-intermittent, top burdens can be trying to oversee. This is considerably more so for unstructured information. What's more, information pattern extraction and estimating represent an extra challenge.

2. Volume of data. Data start from an assortment of sources, including business exchanges, internet based life, sensor-to-gadget information, machine-to-machine information, and biomedical information for people. The volumes of such data are massive.

3. Data Complexity of data. Data as a rule originate from different sources, making it hard to interface, coordinate, wash down, and move crosswise over frameworks. In any case, it is important to interface and associate information connections, chains of command, and different information linkages, before them rapidly winding wild.

4. Data dynamic. Sign are all over, yet for the most part land from some obscure source, and blended with a few sign and maybe their echoes. Partition of the spotless sign from a visually impaired source is a test; and all the more in this way, if continuous execution is wanted.

5. Transmission of data. data at an exceptional speed must be managed in an opportune way. This issue is significantly additionally trying for two-way or multi-party information correspondence.
6. Variety of data. Data come in a wide range of configurations: from organized numeric information in customary information bases to unstructured content reports, from non-numeric information to huge interpersonal organization and messages interchanges, just as from compacted video and sound to stock ticker information and monetary exchange. All these must be overseen and prepared as needs be.

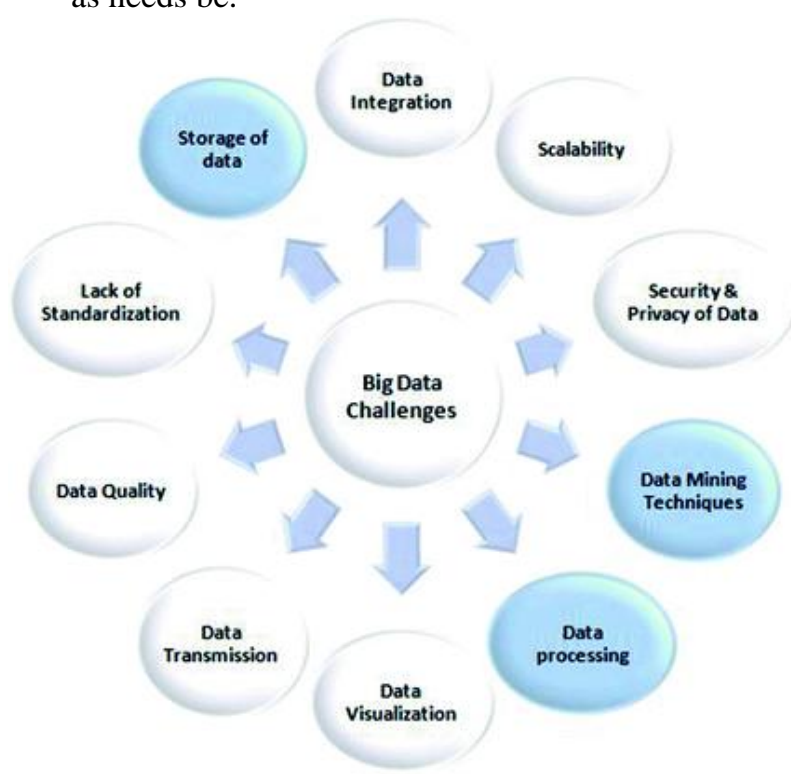

Figure 6: Challenges of Big data

\section{MATHEMATICS IN HEALTH CARE WITH APPLICATIONS}

In healthcare field math plays a vital role. For diagnose, treat medical problems and presentation reliable calculations and data are must obtained by medical providers. Some mathematical applications in healthcare are as follows [13]:

1. Operating Room applications

The right levels of oxygen for surgical patients and concoct safe solutions Math is basic to helping anesthesiologists. Variables considered by anesthesiologists like the amount of dilution needed, solution dosages or desired drug, weight of patient etc.

2. Vital Signs taking

Blood pressure, pulse rate, breathing rate and temperature are considering as vital signs, as the dashboard indicators of our body it serve. For these signs and for measure them how to read the instruments must know by nurses and medical assistants.

\section{The Bottom Line}

The administrators oversee the money related issue and the administrators oversee the finances loss and profits of the health care facilities. When the patient is receives or admitted outpatient services generally the medical centers count revenue.

\section{Medications Dispensing}

Attendants must make an interpretation of medicine orders into the correct dosages and number of pills to manage. Basically, the quantity of pills

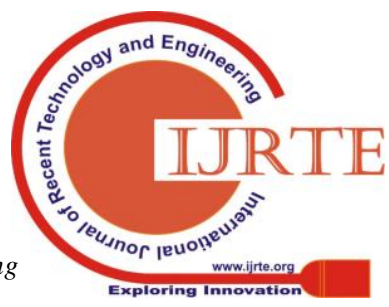


required equivalents the measurement wanted isolated by the dose the emergency clinic has close by.

\section{ESSENTIAL MATH FOR DATA SCIENCE}

Mathematics is the bedrock of any contemporary order of science. Practically every one of the systems of current information science, including AI, have a profound scientific supporting.

It's a given that it will totally require the various pearls of learning - programming capacity, some measure of business astuteness, and exceptional scientific and curious outlook - about the information to work as a top information researcher. Be that as it may, it generally pays to know the apparatus in the engine, instead of simply being the individual in the driver's seat with no information about the vehicle. In this manner, a strong comprehension of the scientific apparatus behind the cool calculations will give an edge among friends [14].

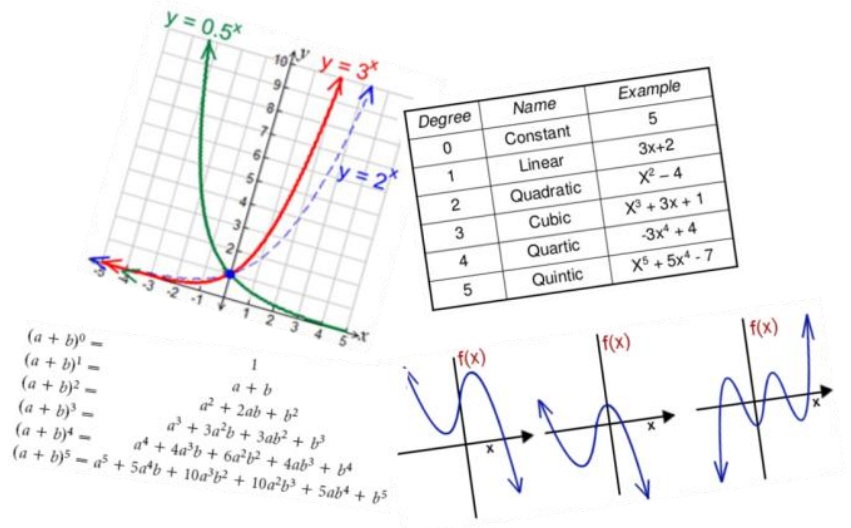

Figure 7: Math functions

Think about a web engineer or business investigator. They might manage a great deal of information and data every day, except there may not be an accentuation on thorough displaying of that information. Frequently, the accentuation is on utilizing the information for a prompt need and proceeding onward, as opposed to on profound logical investigation. Information science, then again, ought to consistently be about the science (not the information). Following that string, certain devices and systems become crucial. Most are the signs of the sound logical procedure [15]:

1. From the stream of information hidden pattern identification

2. By probing the underlying dynamics modeling the process

3. Limitation of a model understanding

4. Around the predictions and data quantifying the uncertainty

5. Hypotheses construction

6. The mathematical abstract logic and proof understanding

7. The quality of the data source rigorously estimated

\section{CONCLUSION}

Every day the industry of healthcare generate a copious amount of data. Mathematics is the bedrock of any contemporary order of science. Practically every one of the systems of current information science, including AI, has a profound scientific supporting. In healthcare field math plays a vital role. For diagnose, treat medical problems and presentation reliable calculations and data are must obtained by medical providers. Across the world the data scientists are gradually revolutionizing the healthcare industry of healthcare with the help of advanced analytics and machine learning.

\section{REFERENCES}

[1] Loukides, M.: What is data science, Big Data Now. Current Prespectives from O'Reilly Radar. Media, Inc., Sebastopol (2011).

[2] Kitchin, R.: Big Data-hype or revolution? In: Sloan, L., Quan-Haase, A. (eds.) The SAGE Handbook of Social Media Research Methods, p. 27. SAGE, Beverley Hills (2017).

[3] Tang, R., Sae-Lim, W.: Data science programs in US higher education: an exploratory content analysis of program description, curriculum structure, and course focus. Educ. Inf. 32(3), 269 (2016).

[4] Bandeira, A.S.: Ten lectures and forty-two open problems in the mathematics of data science. Lecture Notes (2015).

[5] Loyiso G. Nongxa, "Mathematical and statistical foundations and challenges of (big) data sciences", S. Afr. j. sci. vol.113 n.3-4 Pretoria Mar./Apr. 2017.

[6] Li Chen,Zhixun, SuBo Jiang, "Relationship and Connectivity of Incomplete Data Collection", Dec 2015.

[7] AssuncaoD, CalheirosRN, Bianchi S, Netto MAS, BuyyaR (2013) Big Data Computing and Clouds: Challenges, Solutions, and Future Directions.J.ParallelDistrib. Comput. 79: 3-1.

[8] Markham AN (2013) Undermining 'data': A critical examination of a core tem of scientific inquiry.

[9] (2012) WEF (World Economic Forum) \& Vital Wave Consulting. Big Data, Big Impact: New Possibilities for International Development.

[10] ManyikaJ, Chui M, BughinJ, Brown B, Dobbs R et al., (2011) Big Data: The next frontier for innovation, competition, and productivity.

[11] Liang Y1, Kelemen A (2007) Bayesian state space models for inferring and predicting temporal gene expression profiles. Biom J 49: 801-814

[12] Liang Y1, Kelemen A (2011) Sequential Support Vector Regression with Embedded Entropy for SNP Selection and Disease Classification. Stat Anal Data Min 4: 301-312.

[13] Kelemen A1, Vasilakos AV, Liang Y (2009) Computational intelligence in bioinformatics: SNP/haplotype data in genetic association study for common diseases. IEEE Trans InfTechnol Biomed 13: 841-847.

[14] Willcox, K., Bounova, G.: Mathematics in engineering: identifying, enhancing and linking the implicit mathematics curriculum. In: Proceeding of the 2004 American Society for Engineering Education Annual Conference and Exposition, American Society for Engineering Education, pp. 1-13 (2004).

[15] Hughes, T.J.: The Finite Element Method: Linear Static and Dynamic Finite Element Analysis. Courier Corporation, North Chelmsford (2012).

[16] Nguyen, V.P., Anitescu, C., Bordas, S.P., Rabczuk, T.: Isogeometric analysis: an overview and computer implementation aspects. Math Comput. Simul. 117, 89 (2015). 